Article

\title{
Synthesis of Double-Shelled Hollow Inorganic Nanospheres through Block Copolymer-Metal Coordination and Atomic Layer Deposition
}

\author{
Nina Yan ${ }^{1,2}{ }^{10}$, Qingbao Guan ${ }^{3}{ }^{-}$, Zhiming Yang ${ }^{4}$, Min Feng ${ }^{1,2}$, Xizhi Jiang ${ }^{1,2}$, Jun Liu ${ }^{1,2}$ \\ and Lei $\mathrm{Xu} 1,2, *$ (D) \\ 1 Institute of Agricultural Facilities and Equipment, Jiangsu Academy of Agricultural Sciences, \\ Nanjing 210014, China \\ 2 Key Laboratory for Protected Agricultural Engineering in the Middle and Lower Reaches of Yangtze River, \\ Ministry of Agriculture and Rural Affairs, Nanjing 210014, China \\ 3 State Key Laboratory for Modification of Chemical Fibers and Polymer Materials, International Joint \\ Laboratory for Advanced Fiber and Low-dimension Materials, College of Materials Science and Engineering, \\ Donghua University, Shanghai 201620, China \\ 4 Jiangsu Bi-gold New Material Stock Co., Ltd., Zhenjiang 212400, China \\ * Correspondence: xulei@jaas.ac.cn; Tel.: +86-187-6187-0203
}

Received: 24 May 2019; Accepted: 6 July 2019; Published: 19 July 2019

\begin{abstract}
Double-shelled hollow (DSH) structures with varied inorganic compositions are confirmed to have improved performances in diverse applications, especially in lithium ion battery. However, it is still of great challenge to obtain these complex nanostructures with traditional hard templates and solution-based route. Here we report an innovative pathway for the preparation of the DSH nanospheres based on block copolymer self-assembly, metal-ligand coordination and atomic layer deposition. Polymeric composite micelles derived from amphiphilic block copolymers and ferric ions were prepared with heating-enabled micellization and metal-ligand coordination. The DSH nanospheres with $\mathrm{Fe}_{2} \mathrm{O}_{3}$ stands inner and $\mathrm{TiO}_{2}$ outer the structures can be obtained with atomic layer deposition of a thin layer of $\mathrm{TiO}_{2}$ followed with calcination in air. The coordination was carried out at room temperature and the deposition was performed at the low temperature of $80^{\circ} \mathrm{C}$, thus providing a feasible fabrication strategy for DSH structures without destruction of the templates. The cavity and the outer layer of the structures can also be simply tuned with the utilized block copolymers and the deposition cycles. These DSH inorganic nanospheres are expected to find vital applications in battery, catalysis, sensing and drug delivery, etc.
\end{abstract}

Keywords: block copolymers; self-assembly; metal-ligand coordination; atomic layer deposition; double-shelled hollow structures

\section{Introduction}

Metal oxides, such as $\mathrm{Fe}_{2} \mathrm{O}_{3}$ and $\mathrm{TiO}_{2}$ with low density and high theoretical capacities are widely applied in lithium ion battery [1,2] and photocatalysis [3]. However, their performances are usually limited with low surface area and poor conductivity [3]. To enhance the performance of these materials, hollow structures are proven to be an efficient way as the cavity of the structures can provide extra surface for exposure and decreased electron/ion transport pathways [4]. Meanwhile, compared with hollow structures containing single shell of one composition, double-/multiple-shelled hollow (DSH/MSH) structures with varied compositions are confirmed to broaden their properties or improve their performance [4-6]. For example, Zhou and co-workers found that the hollow $\mathrm{SnO}_{2} @ \mathrm{TiO}_{2}$ spheres 
exhibit better electrochemical performance than hollow $\mathrm{SnO}_{2}$ spheres [4]. However, fabrication of these complex nanoarchitectures is still challenging and less reported.

The fabrication of hollow structures is usually composed of the utilization of the hard templates, such as $\mathrm{SiO}_{2}$ and PS nanospheres, followed with a solution-based route [3,4]. Nowadays, block copolymers are emerging as promising templates for the preparation of numerous hollow structures with functional performance [7], such as metallic compound arrays [8], silicas [9] and carbon materials [10] as they can be self-assembled into diverse well-defined structures due to the two or more thermodynamically incompatible homopolymer chains [11]. Most importantly, block copolymers are considered to have tunable chemical properties, for example, chromophores with hydrophobic interactions [12], quaternization [13] or metal ion coordination with the polyelectrolyte chains [14], thus providing additional functions in the systems.

Compared with solution-based route for the growth of metal oxides, atomic layer deposition (ALD) was applied recently for the production of nanoscopic metal oxides with templates, including $\mathrm{TiO}_{2}, \mathrm{Al}_{2} \mathrm{O}_{3}, \mathrm{ZnO}, \mathrm{ZrO}_{2}$, etc. [8,15-17]. This is a gas-phase deposition technique based on self-limiting reactions between alternately supplied gaseous precursors. Namely, ALD is a simple and reliable pathway for the deposition of monolayer target coatings regardless of the substrates, allowing conformal growth of sub-nanometer precision in coating thickness. Therefore, it is of great simplicity to build double-shelled structures on templates with varied compositions based on ALD strategy. For example, Feng fabricated a hybrid metal oxides with $\mathrm{ZnO}$ and $\mathrm{TiO}_{2}$ on hydrophilic carbon nanotubes [18]; Wei deposited $\mathrm{WO}_{3}$ and $\mathrm{Ga}_{2} \mathrm{O}_{3}$ on $\mathrm{SiO}_{2} / \mathrm{Si}$ substrates in sequence for the fabrication of $\mathrm{C}_{2} \mathrm{H}_{5} \mathrm{OH}$ sensors with heterostructures [19]. However, even though the deposition of some metal oxides, such as $\mathrm{TiO}_{2}$ and $\mathrm{Al}_{2} \mathrm{O}_{3}$ can be carried out at a low temperature of $\sim 80^{\circ} \mathrm{C}[15,20,21]$, the deposition of the other target materials usually need to be performed at quite high temperatures. For example, the deposition of $\mathrm{Fe}_{2} \mathrm{O}_{3}$ are usually carried out at the temperature of $250-500{ }^{\circ} \mathrm{C}[22,23]$ and $\mathrm{ZrO}_{2}$ are deposited at over $160{ }^{\circ} \mathrm{C}[17,24]$. For block copolymer templates, they may be destroyed under these high temperatures, thus ruining the well-defined structures.

Here, we proposed an innovative methodology for the preparation of DSH nanospheres based on block copolymer self-assembly, metal-ligand coordination and atomic layer deposition. The metal ions of ferric were first coordinated with the hydrophilic corona, which will transfer to metal oxides eventually. Afterwards, low-temperature ALD was carried out for the deposition of the second layer of $\mathrm{TiO}_{2}$. Both the two steps are aimed at avoiding the decomposition of the block copolymers and the destruction of the nanospheres. Calcination was finally applied for acquiring the DSH structures. The preparation and the morphologies of the micelles and the nanospheres were carefully investigated. The crystal form of the ferric element after calcination was also explored.

\section{Materials and Methods}

\subsection{Materials}

The amphiphilic diblock copolymers of polystyrene-block-poly (4-vinyl pyridine) (PS- $b$-P4VP) with three different molecular weights were purchased from Polymer Source Inc., Dorval, Quebec, Canada. The details of these polymers were given in Table 1. Ferric chloride $\left(\mathrm{FeCl}_{3}\right)$ as well as the solvents including acetic acid and ethanol were provided from local suppliers with analytical purity and used as received. Titanium tetrachloride $\left(\mathrm{TiCl}_{4}\right)$ with a purity of $99.99 \%$ was obtained from Nanjing University. Deionized water with the conductivity of $9.6 \mu \mathrm{S} \mathrm{cm}^{-1}$ was used in all experiments.

Table 1. The molecular weights and the polydispersity of the block copolymers.

\begin{tabular}{cccc}
\hline Block Copolymers & $\boldsymbol{M}_{\mathbf{n}}{ }^{\text {PS }}$ & $\boldsymbol{M}_{\mathbf{n}}{ }^{\text {P4VP }}$ & Polydispersity \\
\hline PS- $b$-P4VP-1 & 75,000 & 25,000 & 1.09 \\
PS- $b$-P4VP-2 & 50,000 & 17,000 & 1.15 \\
PS- $b$-P4VP-3 & 23,000 & 4,500 & 1.10 \\
\hline
\end{tabular}




\subsection{Preparation of Polymeric Composite Micelles by Coordination}

The amphiphilic block copolymer micelles were first prepared following the one-step strategy of the heating-enabled micellization in polar solvents [25]. To be specific, designated block copolymers were first mixed with acetic acid with a concentration of $0.2 \mathrm{wt} \%$. The mixture was then transferred into an oven preheated to $110{ }^{\circ} \mathrm{C}$ and kept unstirred at this temperature for $17 \mathrm{~h}$. The mixture was subsequently cooled down to room temperature naturally and the milky micellar solution was thus obtained. For the coordination of the micelles with ferric ions, $\mathrm{FeCl}_{3}$ was first dissolved in ethanol with a weight percentage of $2 \mathrm{wt} \%$. After ultrasonicated for $10 \mathrm{~min}$, the ferric solution was mixed together with the as-prepared micellar solution with the volume ratio of $1 / 4$. The coordination was carried out for over $24 \mathrm{~h}$ and the mixture became yellowish eventually. The as-obtained polymeric composite micelles were then collected from the mixed solutions by centrifugation at $3000 \mathrm{rpm}$ for $2 \mathrm{~min}$ and further washed with ethanol four times to remove unreacted $\mathrm{FeCl}_{3}$. The composite micelles were redispersed in $2 \mathrm{~mL}$ deionized water and then diluted 20 times for further utilization.

\subsection{Preparation of the DSH Inorganic Nanospheres}

$50 \mu \mathrm{L}$ polymeric composite micellar solution was deposited on each piece of substrates, such as pre-cleaned silicon wafers or carbon-coated copper grids, and the substrates were then dried at the temperature of $60{ }^{\circ} \mathrm{C}$ for $2 \mathrm{~h}$. After that, the samples were placed in the reaction chamber of a commercialized ALD reactor (Savannah S100, Cambridge NanoTech, USA) preheated to $80^{\circ} \mathrm{C}$. The deposition was carried out at this temperature for different numbers of ALD cycles with a steady $\mathrm{N}_{2}$ flow rate of $20 \mathrm{sccm}$. $\mathrm{TiCl}_{4}$ and deionized water were introduced alternatively into the chamber as the $\mathrm{Ti}$ and $\mathrm{O}$ precursors for $\mathrm{TiO}_{2}$ deposition. The typical ALD cycle consists of pulse, exposure and purge of the $\mathrm{TiCl}_{4}$ and water vapor with the time of $0.015,8$ and $15 \mathrm{~s}$, respectively. The cycle was repeated for 50, 100, 300 or 500 times. After $\mathrm{ALD}$ of $\mathrm{TiO}_{2}$, the samples were heated to $540{ }^{\circ} \mathrm{C}$ at a rate of $9^{\circ} \mathrm{C} / \mathrm{min}$ and calcinated at this temperature for $3 \mathrm{~h}$ in order to prepare the DSH inorganic nanospheres.

\subsection{Characterizations}

Fourier transformation infrared spectra (FT-IR) of the micelles before and after coordination were characterized by a Nicolet 8700 infrared spectrometer (Thermo Fisher Scientific, Waltham, MA, USA) with the attenuated total reflection mode (ATR). Dynamic light scattering (DLS) was also performed with a particle size analyzer (Zetasizer Nano ZS90, Malvern Panalytical, Malvern, UK) for determining the sizes of the micelles dispersed in water. The morphologies of the samples under different conditions were all examined on silicon wafers with a S-4800 field emission scanning electron microscope (FESEM, Hitachi, Tokyo, Japan) at the accelerating voltage of $5 \mathrm{kV}$. The samples were first vacuum coated with a thin layer of platinum-palladium alloy for the improvement of conductivity. Transmission electron microscopes (TEM, H-600, Hitachi, Tokyo, Japan \& JEM-2100F, JEOL, Tokyo, Japan) were also employed to examine the nanospheres on copper grids before and after ALD. The grids were carefully placed in a small container during the ALD process in order to avoid being pulsed into the vacuum pump. The energy dispersive X-ray spectrometer (EDX) was used to detect the existence of the Fe and Ti elements along with the SEM characterizations and TEM characterizations. X-ray diffraction (XRD) pattern of the nanospheres with $100 \mathrm{TiO}_{2}$ cycles after calcination were obtained from a wide-angle diffractometer with $\mathrm{CuK} \alpha$ radiation $(\lambda=0.154 \mathrm{~nm})$ at a generator voltage of $40 \mathrm{kV}$ and a generator current of $40 \mathrm{~mA}$. The scanning speed and the step were $2.4^{\circ} / \mathrm{min}$ and $0.02^{\circ}$, respectively.

\section{Results}

\subsection{The Polymeric Composite Micelles Prepared by Metal-ligand Coordination}

As the amphiphilic block copolymers are consist of hydrophilic and hydrophobic chains which are covalently linked together, they can self-assembled into either regular or reverse micelles or other nanostructures in selective solvents which are mainly depending on the molecular structures 
of polymers and the polarity of solvents [26]. For example, the regular micelles with hydrophobic cores and hydrophilic corona can be exclusively formed by dissolution of block copolymers in heating polar solvents [25] while the reverse micelles with reverse constructions are able to be formed with the introduction of nonpolar solvents [27]. Meanwhile, it has been reported that $\mathrm{P} 4 \mathrm{VP}$ can function as a ligand to coordinate with metal ions due to the existence of the pyridyl groups [14]. Therefore, amphiphilic block copolymers of PS- $b$-P4VP were employed in this work. The schematic illustration of the preparation route for DSH inorganic nanospheres was depicted in Figure 1. Regular micelles were first prepared with the heating-enabled micellization strategy (Figure 1a). Ferric ions were then introduced for the coordination with the pyridyl groups of the hydrophilic P4VP coronae in order to prepare polymeric composite micelles (Figure 1b). We note that the solution is slightly milky after heating-enabled micellization and it became yellowish after mixing with $\mathrm{FeCl}_{3}$, which may represent the occurrence of the coordination. The reactions can also be confirmed with the infrared spectrometry, as shown in Figure 2a. The peaks centering around 1452 and $1493 \mathrm{~cm}^{-1}$ should correspond to the characteristic of the phenyl rings of the PS blocks [28]. The peaks at 1558 and $1598 \mathrm{~cm}^{-1}$ should be ascribed to the vibration of the $\mathrm{C}=\mathrm{N}$ and $\mathrm{C}=\mathrm{C}$ in pyridine rings of P4VP blocks [28,29]. A new peak centering around $1636 \mathrm{~cm}^{-1}$ was observed with the polymeric composite micelles, which reveals the coordination between the polymer and the ferric ions $[29,30]$. Meanwhile, a slight shift ( 3-4 wavenumbers) at the wavenumber of $1598 \mathrm{~cm}^{-1}$ were also observed with the polymeric composite micelles, thus indicating the interactions of $\mathrm{N}$ atom of pyridine rings with the ferric ions [29].
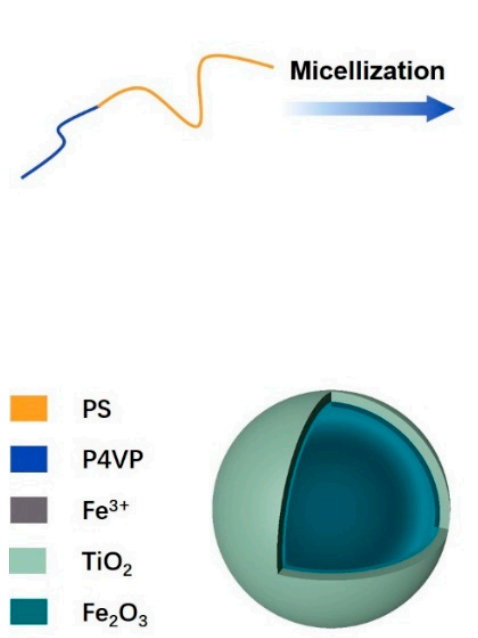

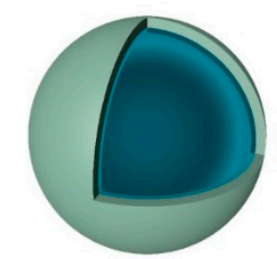

(d)

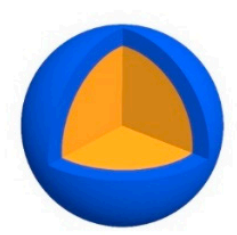

(a)

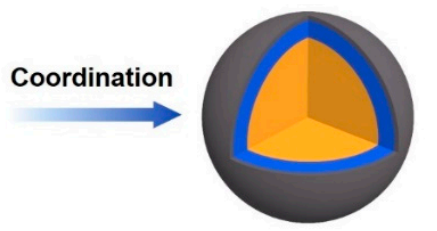

(b)

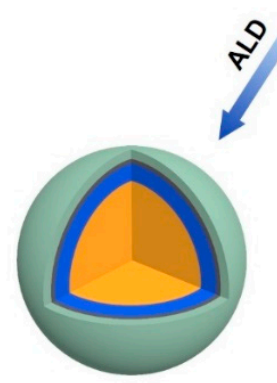

(c)

Figure 1. The schematic diagram for the fabrication of double-shelled hollow (DSH) nanospheres through block copolymer-metal coordination and atomic layer deposition (ALD). (a) The regular micelles prepared by heating-enabled micellization. (b) The polymeric composite micelles after metal-ligand coordination. (c) The nanospheres after $\mathrm{ALD}$ of $\mathrm{TiO}_{2}$. (d) DSH inorganic nanospheres after calcination.

We also examined the size distributions of these composite micelles dispersed in water with DLS, as shown in Figure $2 \mathrm{~b}$. According to the results, all of the polymeric composite micelles showed one single size distribution peak and relatively narrow size distributions in the wet state, which indicates the high uniformity of the obtained polymeric composite micelles. The DLS peaks were centered around 210, 157 and $64 \mathrm{~nm}$ with the micelles derived from PS- $b$-P4VP-1, PS- $b$-P4VP-2 and PS- $b$-P4VP-3, respectively, representing their mean diameters in the solution. This suggested that the micellar size is strongly dependent on the molecular weights of the employed block copolymers and the micelles are supposed to become larger with the increase of the molecular weights. 

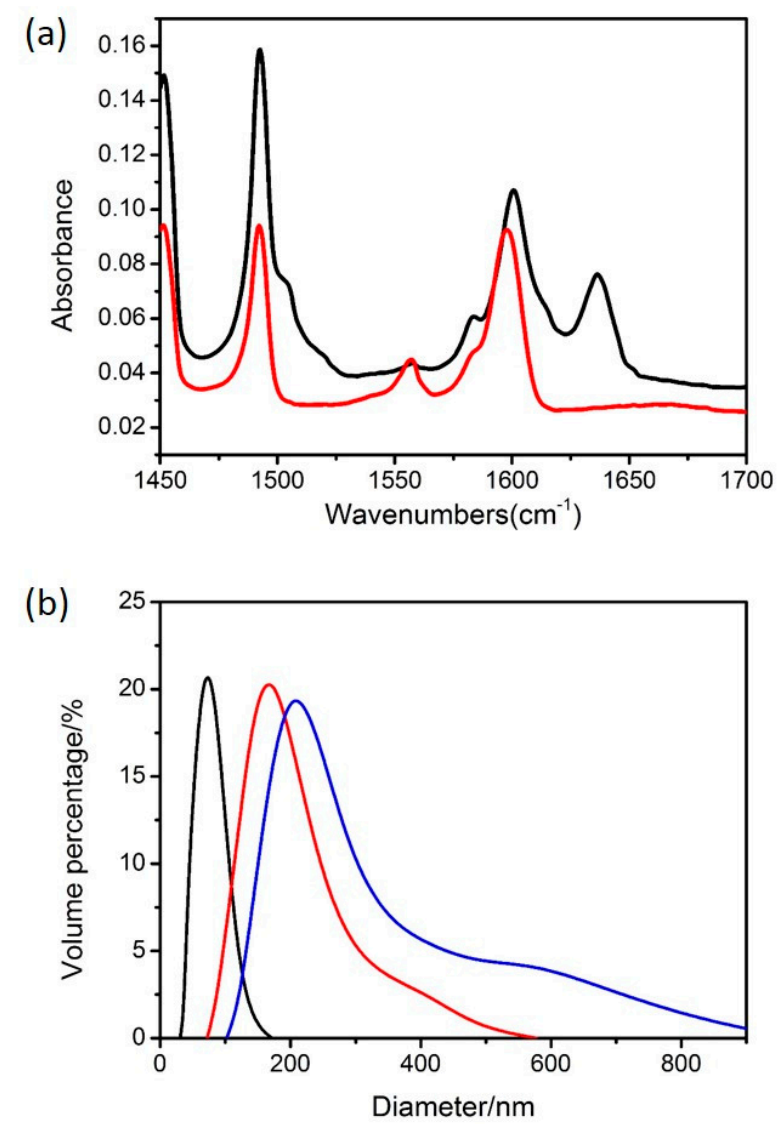

Figure 2. (a) The FT-IR spectra of the micelles of PS- $b$-P4VP-2 before (red) and after (black) complexing with ferric ions. (b) The size distribution curves of the polymeric composite micelles dispersed in water. The curves correspond to PS- $b$-P4VP-3 (black), PS- $b$-P4VP-2 (red) and PS- $b$-P4VP-1 (blue), respectively.

The morphologies of these polymeric composite micelles were examined with a FESEM and the images were shown in Figure 3. Each kind of composite micelles was uniform with a spherical shape and no aggregation can be observed. This should be attributed to the repulsive forces between the coronae. According to the SEM images, the diameters of the composite micelles prepared from PS- $b$-P4VP-1, PS- $b$-P4VP-2 and PS- $b$-P4VP-3 were determined to be $\sim 75, \sim 64$ and $\sim 46 \mathrm{~nm}$, respectively, which were quite smaller than the values acquired from DLS. This should be owing to the totally different states of the micelles with different characterizations. The samples were supposed to be in wet state with a stretching corona P2VP chains under DLS measurements while the samples were in dry state with shrinking P2VP chains under SEM characterizations, thus leading to the obviously different dimensions. However, we note that the diameters in the dry state also increased with the molecular weights of the used block copolymers, which share similar trend with the values in wet state. Therefore, it is of great simplicity to regulate the micelles with molecular structures of the block copolymers.
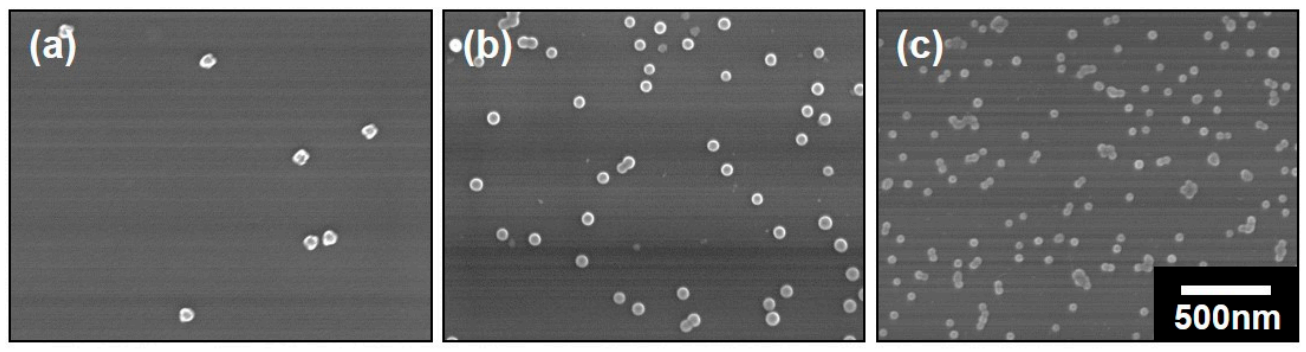

Figure 3. SEM images of the polymeric composite micelles prepared from (a) PS- $b$-P4VP-1, (b) PS- $b$-P4VP-2 and (c) PS- $b-\mathrm{P} 4 \mathrm{VP}-3$. All of the images have the same magnification and the scale bar is shown in (c). 


\subsection{Preparation of the Nanospheres by ALD on the Polymeric Composite Micelles}

The as-prepared polymeric composite micelles with coordinated ferric ions were further utilized as the templates for $\mathrm{TiO}_{2}$ coatings (Figure 1c). A low temperature deposition was employed in this work in order to avoid the destruction or the degradation of the polymer-based micellar templates. The deposition was carried out at $80{ }^{\circ} \mathrm{C}$ for various ALD cycles, which is lower than the glass transition temperatures $\left(T_{\mathrm{g}}\right)$ of both the PS and P4VP blocks $\left(T_{\mathrm{g}}{ }^{\mathrm{PS}}\right.$ is $101-106{ }^{\circ} \mathrm{C}$ and $T_{\mathrm{g}}{ }^{\mathrm{P} 4 \mathrm{VP}}$ is $145-155^{\circ} \mathrm{C}$, respectively, provided by the supplier). This low temperature deposition was also reported elsewhere [20,31,32], thus can be carried out prosperously. Meanwhile, the ferric ions will not be replaced by the titanic precursors, which will be discussed later. The morphologies of the nanospheres derived from PS- $b$-P4VP-1 with various ALD cycles were depicted in Figure 4a-d. We note that the separated micelles are able to maintain their spherical shapes after low temperature deposition regardless of the ALD cycles, thus verified the feasibility of the deposition. The diameters of the nanospheres had a visible increment with the increase of the ALD cycles. To further understand the relationship between the diameters of the nanospheres and the number of ALD cycles, the plot of the mean diameters of the nanospheres with the number of cycles was given in Figure 4e. As discussed in Figure 3a, the diameter of the composite micelles was measured to be $\sim 75 \mathrm{~nm}$ before deposition. After $\mathrm{TiO}_{2}$ deposition for 50, 100, 300 and 500 cycles, the nanospheres were determined to be $\sim 83, \sim 93, \sim 109$ and $\sim 136 \mathrm{~nm}$, respectively, as listed in Table 2 . According to the fitted curves, the diameters of the nanospheres were increased with the number of ALD cycles at an average rate of $\sim 1.16 \AA$ per cycle. However, the growth of the nanospheres with the cycle numbers was nonlinear in fact. The deposition rate is observed to be faster at the first 100 cycles with a mean value of $\sim 1.80 \AA$ than that for the later 400 cycles with the value of $\sim 1.08 \AA$, which may probably be owing to the varied diffusion rate of the precursors. In the initial stage, the intersphere distance is large enough for the rapid diffusion of the precursor vapors. However, with the increment of the ALD cycles, the nanospheres were getting larger with the intersphere space getting reduced correspondingly, thus increased the diffusion resistance of the ALD precursors and lower the deposition rate. The varied deposition substrates may also be an important factor for the changed deposition rate. In the initial stage, the precursors of $\mathrm{TiCl}_{4}$ was supposed to coordinate first with the unreacted superficial free pyridyl groups of P4VP coronae, thus harvested Ti precursors rapidly. Further exposure to the precursors led to the growth of $\mathrm{TiO}_{2}$ on the preformed $\mathrm{TiO}_{2}$ thin layer, which may result in the different growth rate of $\mathrm{TiO}_{2}$ eventually.

Table 2. The diameters of the nanospheres derived from different block copolymers with varied ALD cycles ${ }^{1}$.

\begin{tabular}{cccc}
\hline Cycles & PS- $\boldsymbol{b}$-P4VP-1 & PS- $\boldsymbol{b}$-P4VP-2 & PS- $\boldsymbol{b}$-P4VP-3 \\
\hline 0 & $75 \pm 5$ & $64 \pm 4$ & $46 \pm 4$ \\
50 & $83 \pm 4$ & $71 \pm 3$ & $55 \pm 4$ \\
100 & $93 \pm 7$ & $77 \pm 4$ & $61 \pm 5$ \\
300 & $109 \pm 5$ & $106 \pm 5$ & $85 \pm 6$ \\
500 & $136 \pm 6$ & $135 \pm 5$ & $112 \pm 6$ \\
\hline \multicolumn{4}{r}{}
\end{tabular}

${ }^{1}$ The unit is $\mathrm{nm}$.

The morphologies and the plot of nanospheres derived from PS- $b$-P4VP-2 and PS- $b$-P4VP-3 with different ALD cycles were also shown in Figures S1 and S2. The diameters of these nanospheres were also listed in Table 2. We found that the diameters of both kinds of nanospheres have an increment with the ALD cycles, which is similar to that of the nanospheres prepared from PS- $b$-P4VP-1. The average growth rate for the deposition on PS- $b$-P4VP-2 and PS- $b$-P4VP-3 are $\sim 1.43 \AA$ and $~ 1.29$ $\AA$ per cycle, respectively, which is both close to the growth rate of the deposition on PS- $b$-P4VP-1. However, differ from the nonlinear increase with the PS-b-P4VP-1, the growth rate for the deposition on nanospheres with PS- $b$-P4VP-2 and PS- $b$-P4VP-3 are both found to be nearly linear increased with the number of cycles. This may probably be ascribed to the smaller diffusion rate change of the precursors with initial relatively smaller nanospheres and correspondingly broader intersphere 
distance. Moreover, the thickness of $\mathrm{TiO}_{2}$ layer on composite micelles of PS- $b$-P4VP- 1 is calculated to be only $\sim 4 \mathrm{~nm}$ with 50 ALD cycles and $\sim 9 \mathrm{~nm}$ with 100 ALD cycles. The $\mathrm{TiO}_{2}$ layer was increased to $\sim 17$ and $\sim 33 \mathrm{~nm}$ with 300 and 500 cycles of ALD. The thickness of the $\mathrm{TiO}_{2}$ layer on PS-b-P4VP-2 and PS- $b$-P4VP-3 were both nearly equal to these values under same ALD cycles with a small error of only 2-3 nm. Therefore, it is also a simple way to tune the thickness of the $\mathrm{TiO}_{2}$ layer by changing the ALD cycles. Meanwhile, the nanospheres prepared with lower molecular weight were determined to be smaller than those prepared with higher molecular weight under the same deposition cycles.
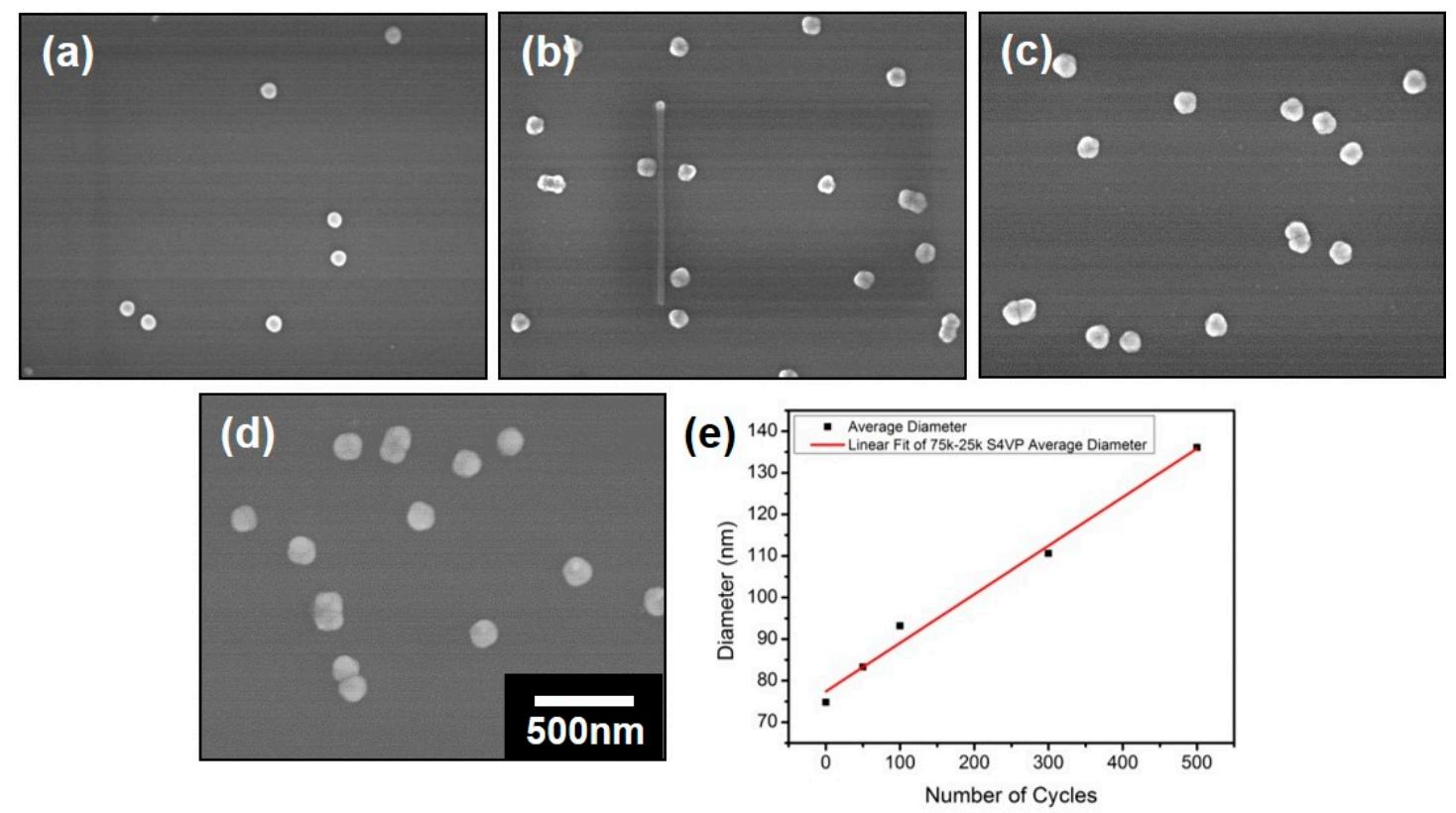

Figure 4. SEM images of the nanospheres of PS- $b$-P4VP-1 subjected to $\mathrm{TiO}_{2}$ deposition for (a) 50, (b) 100, (c) 300 and (d) 500 cycles, respectively. All of the images have the same magnification and the scale bar is shown in (d). (e) The plot of the diameters of the nanospheres with the number of ALD cycles.

The structures of the nanospheres derived from PS- $b$-P4VP-1 with different ALD cycles were also investigated by TEM carefully. As demonstrated in Figure $5 \mathrm{a}$, an ultrathin dark layer with the thickness of $\sim 3 \mathrm{~nm}$ around the polymeric composite micelles was observed without ALD. Considering the similar electron density of PS and P4VP chains, the dark layer should only be ascribed to the presence of the ferric ions as Fe element have higher electron density than that of the polymers [15]. This result illustrated the successful coordination of the ferric ions with the pyridyl groups of the coronae P4VP chains. After ALD of $\mathrm{TiO}_{2}$ for 50 cycles (Figure $5 \mathrm{~b}$ ), the thickness of the dark layer around nanospheres increased to $\sim 6 \mathrm{~nm}$ and it further increased to $\sim 10 \mathrm{~nm}$ after 100 cycles (Figure $5 \mathrm{c}$ ). Therefore, the $\mathrm{TiO}_{2}$ layer is determined to be 3 and $7 \mathrm{~nm}$ with 50 and 100 cycles. Considering the different principles between SEM and TEM characterizations, these values were in good agreement with the results obtained from SEM characterizations. The EDX mapping of the PS- $b$-P4VP-1 nanospheres with 50 ALD cycles was also given in Figure S3. The Fe and Ti elements were both observed while Fe element mainly existed closer to the center of the nanospheres than Ti element. This verified the double-shelled structures after $\mathrm{TiO}_{2}$ deposition with Fe element exists inner and Ti element outer the shell of the nanospheres. Meanwhile, the precursors of $\mathrm{TiCl}_{4}$ will not replace the coordinated ferric ions with the ALD process. The structures of the nanospheres derived from PS- $b$-P4VP-3 with different ALD cycles were also investigated and the results were shown in Figure S4. The dark layer around the polymeric composite micelles was also observed and the size of the nanospheres of PS- $b$-P4VP-3 was found to be much smaller than that of PS- $b$-P4VP-1 with the same ALD cycles. 

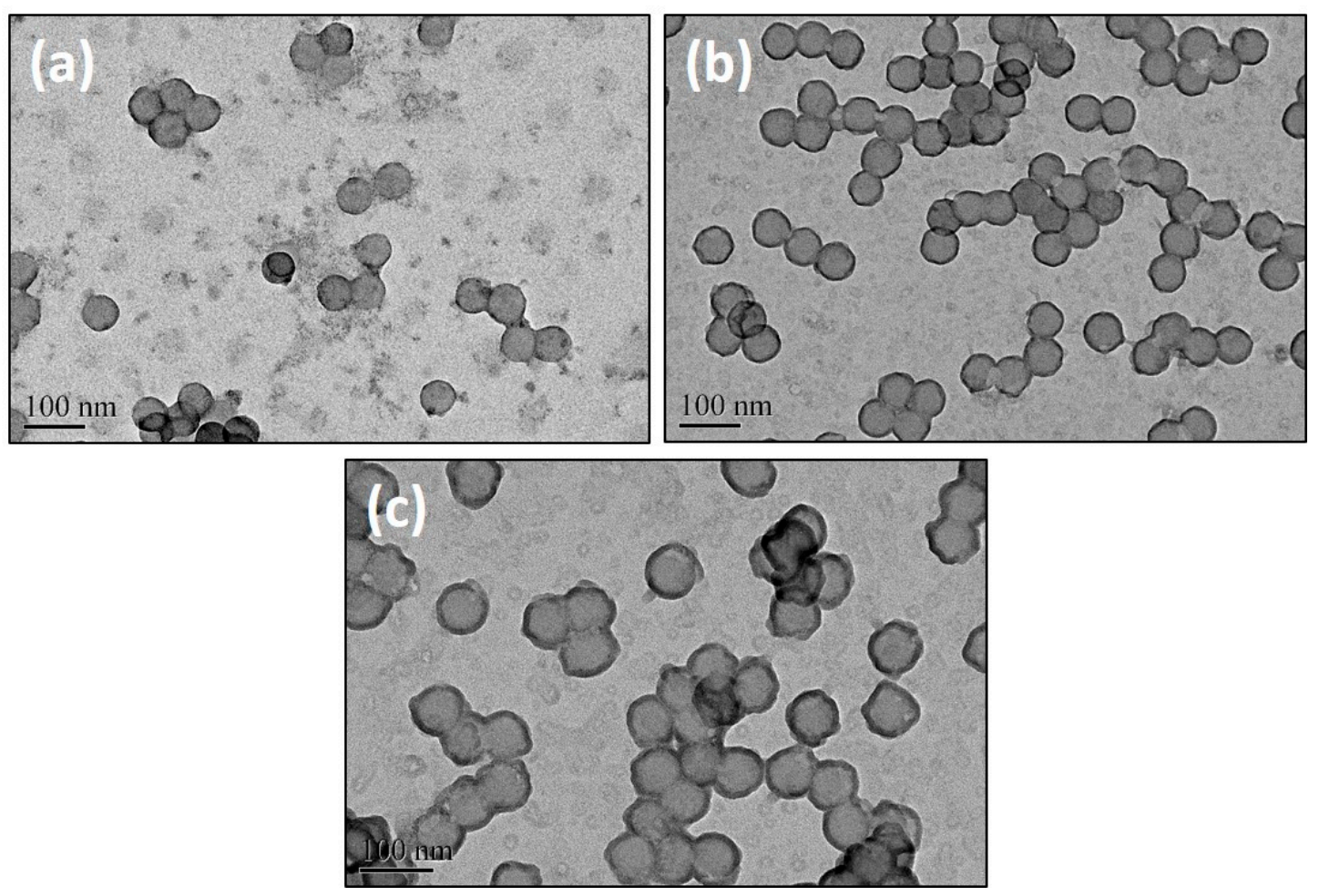

Figure 5. TEM images of the nanospheres of PS- $b$-P4VP-1 subjected to $\mathrm{TiO}_{2}$ deposition for (a) 0, (b) 50 and (c) 100 cycles, respectively.

\subsection{The Preparation of the DSH Inorganic Nanospheres}

In order to prepare DSH structures, the as-deposited nanospheres were calcinated in air at $540{ }^{\circ} \mathrm{C}$ for $3 \mathrm{~h}$. After calcination, the block copolymers were degraded while the coordinated ferric ions were supposed to be transformed into a thin layer of iron oxide and the outer $\mathrm{TiO}_{2}$ layer kept the shell skeleton, leading to the hollow structures. It is also supposed that the calcination leads to the formation of crystalline $\mathrm{TiO}_{2}$ while the $\mathrm{TiO}_{2}$ produced at low temperature was usually weakly crystallized or even amorphous [33]. The morphologies of the nanospheres of PS- $b$-P4VP-1 subjected to $\mathrm{TiO}_{2}$ deposition for different ALD cycles after calcination was depicted in Figure 6. The nanospheres can maintain their spherical structures without any destruction after calcination even if the $\mathrm{TiO}_{2}$ layer was as thin as only $\sim 4 \mathrm{~nm}$ with 50 ALD cycles. Meanwhile, with the increment of the ALD cycles, the diameters of the nanospheres after calcination increased accordingly. For example, the diameter of the nanospheres was determined to be $\sim 62 \mathrm{~nm}$ with 50 cycles (Figure $6 \mathrm{a}$ ) and it can be further increased to $\sim 73, \sim 105$ and $\sim 135 \mathrm{~nm}$ with 100, 300 and 500 cycles (Figure 6b-d). However, it is surprising that the diameters of the nanospheres with lower ALD cycles are decreased when compared with the diameters before calcination. As the ALD carried out for over 300 cycles, the diameters of the nanospheres were nearly the same either before or after calcination, suggesting no deformation of the structures. Therefore, it is believed that the nanospheres were partly shrinked as the thickness of the $\mathrm{TiO}_{2}$ layer is lower than $\sim 17 \mathrm{~nm}$. The morphologies of the nanospheres of PS- $b-\mathrm{P} 4 \mathrm{VP}-2$ after calcination were also shown in Figure S5. The diameters of nanospheres were determined to be $\sim 65 \mathrm{~nm}$ with 50 ALD cycles, which is smaller than the value obtained from SEM characterizations, indicating a shrinkage of the nanospheres after calcination. However, the diameter was supposed to be $\sim 78 \mathrm{~nm}$ with 100 ALD cycles, which is close to the result from SEM characterizations. Therefore, nanospheres derived from lower molecular weights were able to maintain their structures without any deformation with thinner $\mathrm{TiO}_{2}$ layers, for example, $\sim 7 \mathrm{~nm}$. 

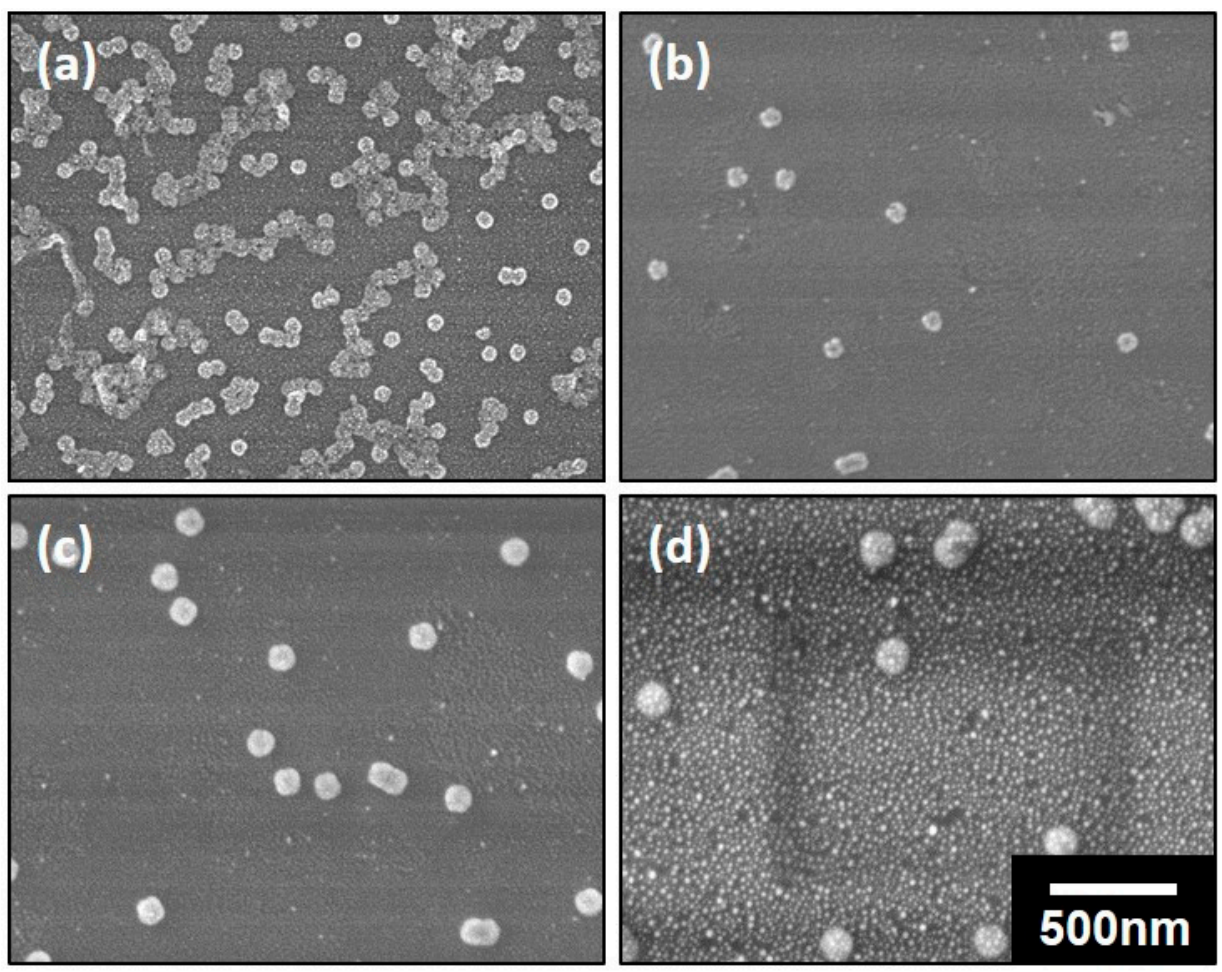

Figure 6. SEM images of the nanospheres of PS- $b$-P4VP-1 subjected to $\mathrm{TiO}_{2}$ deposition for (a) 50, (b) 100, (c) 300 and (d) 500 cycles followed by calcination. All of the images have the same magnification and the scale bar is shown in (d).

To further confirm the existence of the iron and titanium elements after calcination, EDX was utilized for the characterizations of the PS- $b$-P4VP-1 samples and the results were summarized in Table 3. After calcination, the block copolymers were fully degraded as the PS- $b-\mathrm{P} 4 \mathrm{VP}$ can be fully removed at the temperature of over $300^{\circ} \mathrm{C}$ [15]. As evidenced by the results, the iron and titanium elements were still existed in the samples even though their amounts were finite. Considering the nanospheres were sporadically coated on the silicon wafers with a quite thin silica layer existed on the surface, it is reasonable to understand that the amount of Fe and Ti elements are much lower than those of $\mathrm{Si}$ and $\mathrm{O}$ elements. Meanwhile, as the calcination was carried out in air, the ferric ions coordinated on the micelles were considered to be transformed into a thin layer of iron oxide. To further confirm the crystal form of the Fe element, the XRD pattern of the hollow nanospheres of PS- $b$-P4VP-1 with 100 ALD cycles was exhibited in Figure 7. XRD analysis showed that the DSH nanospheres present a peak centering at $33^{\circ}$, which is coincident with a characteristic peak of $\alpha-\mathrm{Fe}_{2} \mathrm{O}_{3}$. Therefore, it indicated a transition of ferric ions to a moderate crystallinity of $\alpha-\mathrm{Fe}_{2} \mathrm{O}_{3}$ after calcination in air and it is credible that the double-shelled polymeric nanospheres are transferred to the DSH inorganic nanospheres with $\mathrm{Fe}_{2} \mathrm{O}_{3}$ exists inner and $\mathrm{TiO}_{2}$ outer the hollow spherical structures.

Table 3. EDX analysis of the hollow nanospheres of PS- $b$-P4VP-1 after ALD and calcination.

\begin{tabular}{ccc}
\hline Element & Weight \% & Atomic \% \\
\hline O K & 6.04 & 10.16 \\
Si K & 93.39 & 89.54 \\
Ti K & 0.32 & 0.18 \\
Fe K & 0.25 & 0.12 \\
Totals & 100.00 & \\
\hline
\end{tabular}




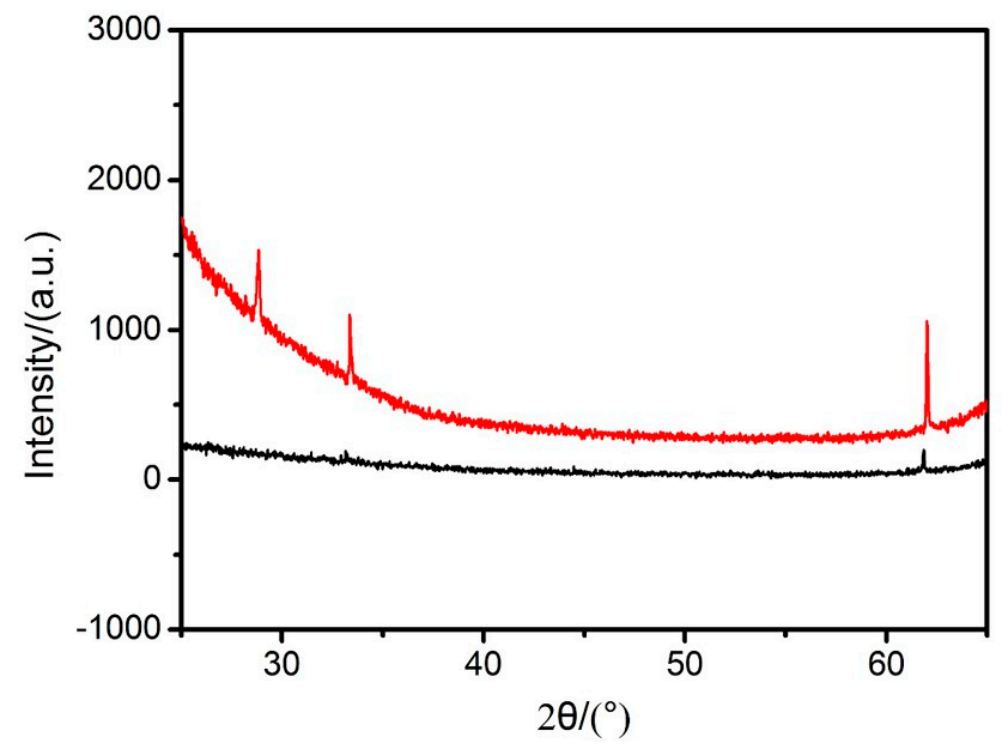

Figure 7. Comparison of the XRD patterns of silicon wafers (black) with the hollow nanospheres of PS- $b$-P4VP-1 after calcination (red).

\section{Conclusions}

We have demonstrated an innovative strategy for producing DSH inorganic nanospheres with the block copolymer micelles being employed as the template. In this strategy, amphiphilic block copolymers were first self-assembled into regular micelles with heating-enabled micellization. With the introduction of the metal-ligand coordination, ferric ions were supposed to be coordinated on the coronae of the regular micelles, forming polymeric composite micelles. The composite micelles were then deposited with a thin layer of $\mathrm{TiO}_{2}$ by ALD and the DSH inorganic nanospheres can be obtained with $\mathrm{Fe}_{2} \mathrm{O}_{3}$ existing inner and $\mathrm{TiO}_{2}$ outer the hollow spherical structures after calcination in air. The coordination was carried out at room temperature and the ALD process was performed at the low temperature of $80^{\circ} \mathrm{C}$. Therefore, this strategy provides a feasible strategy for preparing double-shelled structures without destruction of the block copolymer templates with some designated metal oxide which must be deposited with quite high temperatures. The hollow structures can also be finely tuned with the utilized molecular structures of the block copolymers and the ALD cycles. These DSH inorganic nanospheres are expected to find vital applications in battery, catalysis, sensing and drug delivery, etc.

Supplementary Materials: The following are available online at http:/www.mdpi.com/2073-4360/11/7/1208/s1, Figure S1: SEM images of the nanospheres of PS-b-P4VP-2 subjected to $\mathrm{TiO}_{2}$ deposition for (a) 50 , (b) 100 , (c) 300 and (d) 500 cycles, respectively. All of the images have the same magnification and the scale bar is shown in (d). (e) The plot of the diameters of the nanospheres with the number of ALD cycles, Figure S2: SEM images of the nanospheres of PS-b-P4VP-3 subjected to $\mathrm{TiO}_{2}$ deposition for (a) 50, (b) 100, (c) 300 and (d) 500 cycles, respectively. All of the images have the same magnification and the scale bar is shown in (d). (e) The plot of the diameters of the nanospheres with the number of ALD cycles, Figure S3: EDX mapping of the micelles of PS- $b$-P4VP-1 subjected to $\mathrm{TiO}_{2}$ deposition for 50 cycles, Figure S4: TEM images of the nanospheres of PS- $b$-P4VP-3 subjected to $\mathrm{TiO}_{2}$ deposition for (a) 0, (b) 50 and (c) 100 cycles, respectively, Figure S5: SEM images of the nanospheres of PS-b-P4VP-2 subjected to $\mathrm{TiO}_{2}$ deposition for (a) 50, (b) 100, (c) 300 and (d) 500 cycles followed with calcination. All of the images have the same magnification and the scale bar is shown in (d).

Author Contributions: Conceptualization, N.Y. and Z.Y.; methodology, N.Y.; validation, M.F., and X.J.; formal analysis, Q.G.; investigation, N.Y.; resources, M.F.; data curation, J.L.; writing—original draft preparation, N.Y.; writing - review and editing, Q.G. and L.X.; supervision, L.X.; project administration, L.X.; funding acquisition, L.X.

Funding: This research was funded by Jiangsu Agriculture Science and Technology Innovation Fund, grant number (CX(18)3049).

Acknowledgments: It is also a great pleasure to thank Prof. Yong Wang at Nanjing Tech University for valuable discussions and suggestions. 
Conflicts of Interest: The authors declare no conflict of interest.

\section{References}

1. Cao, K.Z.; Jiao, L.F.; Liu, H.Q.; Liu, Y.C.; Wang, Y.J.; Guo, Z.P.; Yuan, H.T. 3D hierarchical porous alpha-fe2o3 nanosheets for high-performance lithium-ion batteries. Adv. Energy Mater. 2015, 5, 1401421. [CrossRef]

2. Li, X.J.; Li, M.Y.; Liang, J.C.; Wang, X.F.; Yu, K.F. Growth mechanism of hollow $\mathrm{TiO}_{2}(\mathrm{~B})$ nanocrystals as powerful application in lithium-ion batteries. J. Alloys. Compd. 2016, 681, 471-476. [CrossRef]

3. Zhang, M.; Shang, Q.G.; Wan, Y.Q.; Cheng, Q.R.; Liao, G.Y.; Pan, Z.Q. Self-template synthesis of double-shell $\mathrm{TiO}_{2} @ \mathrm{ZIF}-8$ hollow nanospheres via sonocrystallization with enhanced photocatalytic activities in hydrogen generation. Appl. Catal. B Environ. 2019, 241, 149-158. [CrossRef]

4. Xin, W.P.; Gao, T.T.; Zhang, W.Q.; Hu, T.T.; Sun, X.F.; Zhou, G.W. Three-dimensional hollow $\mathrm{SnO}_{2} @ \mathrm{TiO}_{2}$ spheres encapsulated in reduced graphene oxide aerogels as promising anodes for lithium-ion storage. J. Alloys. Compd. 2019, 784, 157-164. [CrossRef]

5. Zheng, Y.; Zhou, T.F.; Zhang, C.F.; Mao, J.F.; Liu, H.K.; Guo, Z.P. Boosted charge transfer in $\mathrm{SnS} / \mathrm{SnO}_{2}$ heterostructures: Toward high rate capability for sodium-ion batteries. Angew. Chem. Int. Ed. 2016, 55, 3408-3413. [CrossRef] [PubMed]

6. Zhou, H.Q.; Wang, Y.M.; He, R.; Yu, F.; Sun, J.Y.; Wang, F.; Lan, Y.C.; Ren, Z.F.; Chen, S. One-step synthesis of self-supported porous $\mathrm{NiSe}_{2} / \mathrm{Ni}$ hybrid foam: An efficient 3D electrode for hydrogen evolution reaction. Nano Energy 2016, 20, 29-36. [CrossRef]

7. Li, X.G.; Lu, Q.F.; Huang, M.R. Self-stabilized nanoparticles of intrinsically conducting copolymers from 5-sulfonic-2-anisidine. Small 2008, 4, 1201-1209. [CrossRef] [PubMed]

8. Li, F.B.; Yao, X.P.; Wang, Z.G.; Xing, W.H.; Jin, W.Q.; Huang, J.; Wang, Y. Highly porous metal oxide networks of interconnected nanotubes by atomic layer deposition. Nano Lett. 2012, 12, 5033-5038. [CrossRef]

9. Joo, S.H.; Ryoo, R.; Kruk, M.; Jaroniec, M. Evidence for general nature of pore interconnectivity in 2-dimensional hexagonal mesoporous silicas prepared using block copolymer templates. J. Phys. Chem. B 2002, 106, 4640-4646. [CrossRef]

10. Carriazo, D.; Pico, F.; Gutierrez, M.C.; Rubio, F.; Rojo, J.M.; del Monte, F. Block-copolymer assisted synthesis of hierarchical carbon monoliths suitable as supercapacitor electrodes. J. Mater. Chem. 2010, 20, 773-780. [CrossRef]

11. Abetz, V.; Simon, P.F.W. Phase behaviour and morphologies of block copolymers. In Block Copolymers I.; Abetz, V., Ed.; Springer: Berlin/Heidelberg, Germany, 2005; Volume 189, pp. 125-212.

12. Yang, Z.M.; Wang, Z.G.; Yao, X.P.; Chen, X.Q.; Wang, Y. Responsive, fluorescent micellar nanospheres of amphiphilic block copolymers for the characterization of membrane pores. J. Membr. Sci. 2013, 441, 9-17. [CrossRef]

13. Zhang, Z.Z.; Rahman, M.M.; Abetz, C.; Bajer, B.; Wang, J.L.; Abetz, V. Quaternization of a polystyrene-block-poly(4-vinylpyridine) isoporous membrane: An approach to tune the pore size and the charge density. Macromol. Rapid Commun. 2019, 40, 1800729. [CrossRef] [PubMed]

14. Aizawa, M.; Buriak, J.M. Nanoscale patterning of two metals on silicon surfaces using an ABC triblock copolymer template. J. Am. Chem. Soc. 2006, 128, 5877-5886. [CrossRef]

15. Ras, R.H.A.; Kemell, M.; de Wit, J.; Ritala, M.; ten Brinke, G.; Leskela, M.; Ikkala, O. Hollow inorganic nanospheres and nanotubes with tunable wall thicknesses by atomic layer deposition on self-assembled polymeric templates. Adv. Mater. 2007, 19, 102-106. [CrossRef]

16. Xiong, S.; Yang, Y.; Zhong, Z.X.; Wang, Y. One-step synthesis of carbon-hybridized zno on polymeric foams by atomic layer deposition for efficient absorption of oils from water. Ind. Eng. Chem. Res. 2018, 57, 1269-1276. [CrossRef]

17. Selvaraj, S.K.; Parulekar, J.; Takoudis, C.G. Selective atomic layer deposition of zirconia on copper patterned silicon substrates using ethanol as oxygen source as well as copper reductant. J. Vac. Sci. Technol. A 2014, 32, 010601. [CrossRef]

18. Feng, J.; Xiong, S.; Wang, Y. Atomic layer deposition of hybrid metal oxides on carbon nanotube membranes for photodegradation of dyes. Compos. Commun. 2019, 12, 39-46. [CrossRef]

19. Wei, Z.; Akbari, M.K.; Hai, Z.Y.; Ramachandran, R.K.; Detavernier, C.; Verpoort, F.; Kats, E.; Xu, H.Y.; $\mathrm{Hu}$, J.; Zhuiyko, S. Ultra-thin sub- $10 \mathrm{~nm} \mathrm{Ga}{ }_{2} \mathrm{O}_{3}-\mathrm{WO}_{3}$ heterostructures developed by atomic layer deposition 
for sensitive and selective $\mathrm{C}_{2} \mathrm{H}_{5} \mathrm{OH}$ detection on ppm level. Sens. Actuator B Chem. 2019, 287, 147-156. [CrossRef]

20. Yin, J.; Xu, Q.; Wang, Z.G.; Yao, X.P.; Wang, Y. Highly ordered $\mathrm{TiO}_{2}$ nanostructures by sequential vapour infiltration of block copolymer micellar films in an atomic layer deposition reactor. J. Mater. Chem. C 2013, 1, 1029-1036. [CrossRef]

21. Wang, Q.Q.; Wang, H.H.; Xiong, S.; Chen, R.Z.; Wang, Y. Extremely efficient and recyclable absorbents for oily pollutants enabled by ultrathin-layered functionalization. ACS Appl. Mater. Interfaces 2014, 6, 18816-18823. [CrossRef]

22. Porro, S.; Bejtka, K.; Jasmin, A.; Fontana, M.; Milano, G.; Chiolerio, A.; Pirri, C.F.; Ricciardi, C. A multi-level memristor based on atomic layer deposition of iron oxide. Nanotechnology 2018, 29, 9. [CrossRef] [PubMed]

23. Yan, N.; Qin, L.J.; Li, J.G.; Zhao, F.Q.; Feng, H. Atomic layer deposition of iron oxide on reduced graphene oxide and its catalytic activity in the thermal decomposition of ammonium perchlorate. Appl. Surf. Sci. 2018, 451, 155-161. [CrossRef]

24. Zhong, L.J.; Chen, F.; Campbell, S.A.; Gladfelter, W.L. Nanolaminates of zirconia and silica using atomic layer deposition. Chem. Mater. 2004, 16, 1098-1103. [CrossRef]

25. Yang, Z.M.; Wang, Z.G.; Yao, X.P.; Wang, Y. Water-dispersible, uniform nanospheres by heating-enabled micellization of amphiphilic block copolymers in polar solvents. Langmuir 2012, 28, 3011-3017. [CrossRef] [PubMed]

26. Hamley, I.W. Nanotechnology with soft materials. Angew. Chem. Int. Ed. 2003, 42, 1692-1712. [CrossRef] [PubMed]

27. Krishnamoorthy, S.; Pugin, R.; Brugger, J.; Heinzelmann, H.; Hinderling, C. Nanopatterned self-assembled monolayers by using diblock copolymer micelles as nanometer-scale adsorption and etch masks. Adv. Mater. 2008, 20, 1962-1965. [CrossRef]

28. Yuan, J.J.; Ma, R.; Gao, Q.; Wang, Y.F.; Cheng, S.Y.; Feng, L.X.; Fan, Z.Q.; Jiang, L. Synthesis and characterization of polystyrene/poly(4-vinylpyridine) triblock copolymers by reversible addition-fragmentation chain transfer polymerization and their self-assembled aggregates in water. J. Appl. Polym. Sci. 2003, 89, 1017-1025. [CrossRef]

29. Fan, S.; Luan, Y.; Wang, J.J.; Gao, H.Y.; Zhang, X.W.; Wang, G. Monodispersed poly(4-vinylpyridine) spheres supported Fe(iii) material: An efficient and reusable catalyst for benzylic oxidation. J. Mol. Catal. A Chem. 2015, 404, 186-192. [CrossRef]

30. Yarapathi, R.V.; Reddy, S.M.; Tammishetti, S. Polymer supported ferric chloride: Regiospecific nucleophilic ring opening of epoxides. React. Funct. Polym. 2005, 64, 157-161. [CrossRef]

31. Dallorto, S.; Staaks, D.; Schwartzberg, A.; Yang, X.M.; Lee, K.Y.; Rangelow, I.W.; Cabrini, S.; Olynick, D.L. Atomic layer deposition for spacer defined double patterning of sub-10 nm titanium dioxide features. Nanotechnology 2018, 29, 405302. [CrossRef]

32. Lu, H.; Deng, K.M.; Yan, N.N.; Ma, Y.L.; Gu, B.K.; Wang, Y.; Li, L. Efficient perovskite solar cells based on novel three-dimensional TiO2 network architectures. Sci. Bull. 2016, 61, 778-786. [CrossRef]

33. Mitchell, D.R.G.; Attard, D.J.; Triani, G. Transmission electron microscopy studies of atomic layer deposition $\mathrm{TiO} 2$ films grown on silicon. Thin Solid Films 2003, 441, 85-95. [CrossRef]

(C) 2019 by the authors. Licensee MDPI, Basel, Switzerland. This article is an open access article distributed under the terms and conditions of the Creative Commons Attribution (CC BY) license (http://creativecommons.org/licenses/by/4.0/). 